\title{
Retinal Oxygen Tension Is Higher in Light than Dark
}

\author{
EINAR STEFÁNSSON \\ Duke University Medical Center, Department of Ophthalmology, Durham, North Carolina 27710 and the \\ National Eye Institute, Bethesda, Maryland 20892
}

\begin{abstract}
The oxygen tension at the inner retinal surface in rabbits was measured with intraocular polarographic electrodes. In the air breathing rabbit, the oxygen tension is $21 \pm 9 \mathrm{~mm} \mathrm{Hg}$ (mean $\pm 1 \mathrm{SD}, n=6$ ) in 12 footcandles white light at the cornea. The oxygen tension falls $6 \pm 2 \mathrm{~mm} \mathrm{Hg}$ (mean $\pm 1 \mathrm{SD}, n=4, p<0.02$ ) in darkness. In bright white light ( 800 foot-candles), the retinal oxygen tension is about $6 \mathrm{~mm} \mathrm{Hg}$ higher than at 12 foot-candles. The in vivo retinal oxygen consumption was calculated to be $2.4 \mathrm{ml} \mathrm{O} / 100 \mathrm{~g} / \mathrm{min}$ in light and $2.6 \mathrm{ml} \mathrm{O} / 100 \mathrm{~g} / \mathrm{min}$ in dark. The higher oxygen consumption is probably responsible for the lower oxygen tension of the retina in dark as compared to light. Breathing $100 \%$ oxygen elevates the preretinal oxygen tension to $190 \pm 72 \mathrm{~mm} \mathrm{Hg}$ (mean \pm 1 $\mathrm{SD}, n=4$ ) in light. (Pediatr Res 23: 5-8, 1988)
\end{abstract}

\section{Abbreviations}

$P(x)$, oxygen tension at distance $\times$ from Bruch's membrane $Q$, retinal oxygen consumption

$Q_{i}$, inner retinal oxygen consumption

$Q_{o}$, outer retinal oxygen consumption

$D$, diffusion constant for oxygen

$k$, solubility constant for oxygen

$\mathrm{x}_{\mathrm{L}}$, thickness of retina

$x_{\mathrm{a}}$, thickness of outer retina

$P$, oxygen tension

$\mathrm{D}$, diffusion constant for oxygen

The physiological effects of light and oxygen on the retina are of considerable general interest and specifically play a role in the pathogenesis of retinopathy of prematurity. Retinopathy of prematurity has long been known to be related to oxygen breathing (1). Recently, Glass et al. (2) reported that bright lights also contribute to the development of retinopathy of prematurity. This report shows that light elevates the retinal oxygen tension in rabbits. Therefore, illumination may not be an independent risk factor for the development of retinopathy of prematurity, but rather acts through raising the retinal oxygen tension. The report also shows that preretinal oxygen levels rise to levels above the hemoglobin saturation level when the rabbits breathe $100 \%$ oxygen. The extraordinarily high oxygen tension of the retina in hyperoxia may help explain the sensitivity of the immature retina to oxygen breathing. Also a method to calculate the retinal oxygen consumption in vivo is shown, and the oxygen consumption calculated in light and dark.

Received March 17, 1987; accepted August 19, 1987.

Correspondence and reprint requests Einar Stefansson, M.D., Ph.D., Duke University Medical Center, Department of Ophthalmology, Box 3802, Durham. NC 27710

Supported in part by a Career Development Award from the Veterans Administration.

\section{MATERIALS AND METHODS}

Six New Zealand Red rabbits were anesthetized with ketamine hydrochloride $(20-30 \mathrm{mg} / \mathrm{kg}$ intramuscularly) and anesthesia was maintained with alphachloralose $(80 \mathrm{mg} / \mathrm{kg}$ intravenously). The pupils were dilated with $2.5 \%$ phenylephrine and $1 \%$ tropicamide on the cornea. The rabbits were intubated and mechanically ventilated. A femoral artery was cannulated for continuous arterial blood pressure measurements and arterial blood oxygen and carbon dioxide tension, $\mathrm{pH}$ (blood gas analyzer, Instrumentation Laboratory Inc., Lexington, MA, model 713), and hematocrit determinations (Table 1). The electrocardiogram and rectal temperature were continuously monitored and body temperature maintained close to $38^{\circ} \mathrm{C}$ with a heating pad. The animal was placed in a stereotactic head holder. A lateral canthotomy and a conjunctival peritomy were performed. Holding ties were placed under two recti muscles. The sclera was punctured with a cannula in the area of the pars plana of the ciliary body and the polarographic oxygen electrode (Diamond Electrotech Inc., MI, model 760) placed in the vitreous gel approximately $0.1 \mathrm{~mm}$ in front of the avascular retina as described previously $(3,4)$. The preretinal oxygen tension was measured continuously while the light levels varied between darkness when the room was darkened and the animal's head covered with a thick black cloth and 12 footcandles of white light (General Electric Inc., Fairfield, CT, "Watt Miser 35") measured at the corneal level with the pupil fully dilated. In one experiment (two eyes), the light level was varied between dark, room light (12 foot-candles), and the Zeiss operating microscope light with the illuminance at the cornea measuring 800 foot-candles and the measurement performed on the illuminated area of retina. A plano-concave corneal contact lens was in place during the experiments. This eliminates the refractive power of the cornea and reduces the refractive power of the eye to the degree that little focusing of the diffuse lights takes place and insignificant magnification of the probe in the vitreous cavity is seen. The illuminance measured at the corneal level should be close to the illuminance at the retinal surface. However, a more detailed analysis of the optics of the rabbit eye is necessary to exactly quantitate the illuminance at the retina.

Oxygen consumption calculation. The avascular portion of the rabbit retina is a $0.18-\mathrm{mm}$ thick layer of tissue that receives oxygen from the choroid. Alm and Bill (5) showed that the oxygen tension in venous choroidal blood in the cat is almost the same as arterial blood due to the relatively great blood flow rate. The oxygen extraction in the uvea is only $1.02 \pm 0.16$ volume percent. Elgin (6) found the arteriovenous oxygen content difference in the dog to be $0.4-0.9$ volume percent and the difference in oxygen tension between arterial blood and uveal venous blood to be only $16 \mathrm{~mm} \mathrm{Hg}$ when the dogs breathed atmospheric air. We consider the choroid a constant tension oxygen source with oxygen tension equal to the arterial blood oxygen tension. The oxygen diffuses from the choroid, through the retina, where it is consumed, and to the vitreous where the oxygen tension is measured. The oxygen tension $(\mathrm{P})$ drop from 
Table 1. Mean arterial blood pressure, MAP ( $\mathrm{mm} \mathrm{Hg}$ ), arterial blood oxygen tension, $\mathrm{PaO}_{2}(\mathrm{~mm} \mathrm{Hg})$, carbon dioxide partial pressure, $\mathrm{PaCO}_{2}(\mathrm{~mm} \mathrm{Hg})$, and $\mathrm{pH}$, hematocrit (\%), and rectal temperature $\left({ }^{\circ} \mathrm{C}\right)($ mean $\pm 1 S D, n=6)$

$\begin{array}{lc}M \mathrm{MAP} & 76 \pm 10 \\ \left.\mathrm{PaO}_{2} \text { (on } 21 \% \mathrm{O}_{2}\right) & 125 \pm 23 \\ \mathrm{PaO}_{2}\left(\text { on } 100 \% \mathrm{O}_{2}\right) & 343 \pm 77 \\ \mathrm{PaCO}_{2} & 40 \pm 5 \\ \text { pH } & 7.40 \pm 0.04 \\ \text { Hematocrit } & 35 \pm 6 \\ \text { Temperature } & 38.0 \pm 0.8\end{array}$

the choroid to the preretinal vitreous is determined by the distance ( $x$ ) from the choroid, the diffusion constant (D), oxygen solubility (k), and the oxygen consumption (Q), as derived from Fick's law of diffusion. The oxygen consumption is the only variable where the same retinal area is measured over time and the thickness, diffusion, and temperature stay constant.

The oxygen flux across the retina is determined by $\mathrm{Dk} \mathrm{dP} / \mathrm{dx}$. In a steady state, the oxygen consumption $\mathrm{Q}$ is related to the second derivative of the oxygen tension, i.e.

$$
\mathrm{Q}=\mathrm{Dk} \frac{\mathrm{d}^{2} \mathrm{P}}{\mathrm{d} \mathrm{X}^{2}}
$$

Equation (1) can be solved to give the retinal oxygen tension at distance $\mathrm{x}$ from the choroid $(\mathrm{P}[\mathrm{x}])$.

$$
\mathrm{P}(\mathrm{x})=\frac{\mathrm{x}^{2} \mathrm{Q}}{2 \mathrm{Dk}}+\mathrm{Bx}+\mathrm{P}(0)
$$

where $\mathrm{P}(\mathrm{O})$ is the oxygen tension at the chorioretinal interface. We assume that at the inner retinal surface $\left(x_{L}\right)$ the flux from the retina into the vitreous is zero in the steady state (7). This is reasonable due to the very low oxygen consumption of the vitreous.

$$
\begin{gathered}
\frac{\mathrm{dP}}{\mathrm{dx}}=0=\frac{\mathrm{Qx}_{\mathrm{L}}}{\mathrm{Dk}}+\mathrm{B} \\
\mathrm{B}=-\frac{\mathrm{Qx}_{\mathrm{L}}}{\mathrm{Dk}}
\end{gathered}
$$

By inserting the value for $\mathrm{B}$ in equation (2) we find:

$$
\mathrm{P}\left(\mathrm{x}_{\mathrm{L}}\right)=\frac{\mathrm{Qx}_{\mathrm{L}}^{2}}{2 \mathrm{Dk}}-\frac{\mathrm{Qx}_{\mathrm{L}}^{2}}{\mathrm{Dk}}+\mathrm{P}(0)
$$

or

$$
P(0)-P\left(x_{L}\right)=\frac{Q_{x_{L}}^{2}}{2 D k}
$$

Alm and Bill (8) demonstrated that $80 \%$ of the oxygen consumption in the cat retina occurs in the outer retina, where the photoreceptors have a high density of mitochondria. For the purposes of calculating the retinal oxygen consumption, we divide the retina into the outer retina with oxygen consumption $\mathrm{Q}_{\mathrm{o}}$ that equals $1.6 \mathrm{Q}$ and the oxygen consumption in the inner retina $\mathrm{Q}_{\mathrm{i}}$ equals $0.4 \mathrm{Q}$, where $\mathrm{Q}$ is the oxygen consumption of the retina as a whole $\left(\mathrm{mlO}_{2}[\mathrm{~min}]^{-1}\right)$.

Equation (6) can be amended for a 2 layer retina to give:

$$
\mathrm{P}(0)-\mathrm{P}\left(\mathrm{x}_{\mathrm{L}}\right)=\mathrm{Q}\left[\frac{\mathrm{Q}_{0 \mathrm{x}} \mathrm{x}^{2} \mathrm{a}}{2 \mathrm{QDk}}+\frac{\mathrm{Q}_{\mathrm{i}}\left(\mathrm{x}_{\mathrm{L}}{ }^{-x_{\mathrm{a}}}\right)}{2 \mathrm{QDk}}\right]
$$

where $\mathrm{x}_{\mathrm{a}}=0.009 \mathrm{~cm}$ is the border between the outer and inner retina (4). The thickness $\left(\mathrm{x}_{\mathrm{L}}\right)$ of the rabbit retina varies with location and the avascular retina averages $0.018 \mathrm{~cm}$. The diffusion constant and solubility, Dk, for oxygen in rabbit cerebral cortex is $2 \times 10^{-5} \mathrm{ml} \mathrm{O}_{2} \mathrm{~atm}^{-1} \mathrm{~cm}^{-1} \min ^{-1}(9,10)$.
Inserting numbers for $\mathrm{Q}_{\mathrm{o}} / \mathrm{Q}(1.6), \mathrm{Q}_{\mathrm{i}} / \mathrm{Q}(0.4), \mathrm{x}_{\mathrm{a}}$ and $\mathrm{x}_{\mathrm{L}}=$ $0.018 \mathrm{~cm}$ (inner border of retina) gives the retinal oxygen consumption $\mathrm{Q}$ as:

$$
\mathrm{Q}=\left[\mathrm{P}(0)-\mathrm{P}\left(\mathrm{x}_{\mathrm{L}}\right)\right] 17.6 \mathrm{mlO}_{2} \mathrm{~min}^{-1} \mathrm{~atm}^{-1}(100 \mathrm{~g})^{-1}
$$

We measure $\mathrm{P}\left(\mathrm{x}_{\mathrm{L}}\right)$ as preretinal oxygen tension and $\mathrm{P}(\mathrm{O})$ as arterial blood oxygen tension and insert in units of atmospheres into equation (8) to calculate the retinal oxygen consumption $\mathrm{Q}$.

\section{RESULTS}

The preretinal oxygen tension in air breathing rabbits in 12 foot-candles white fluorescent light is $21 \pm 9 \mathrm{~mm} \mathrm{Hg}$ (mean \pm 1 $\mathrm{SD}, n=6$ ). When the lights are turned off the preretinal oxygen tension falls $6 \pm 2 \mathrm{~mm} \mathrm{Hg}$ (mean $\pm 1 \mathrm{SD}, n=4, p=0.018$ ) or $24 \pm 9 \%$ (mean $\pm \mathrm{SD}, n=4$ ) (Fig. 1). The oxygen tension difference between the arterial blood and the preretinal vitreous is $105 \pm 26 \mathrm{~mm} \mathrm{Hg}$ (mean $\pm \mathrm{SD}, n=4$ ) in light and this difference is increased by $6 \pm 2 \mathrm{~mm} \mathrm{Hg}$ (mean $\pm \mathrm{SD}, n=4, p$ $=0.018$, two-tailed paired $t$ test) when the lights are turned off. This corresponds to retinal oxygen consumption of $2.4 \mathrm{ml} \mathrm{O}_{2}$ $\min ^{-1} 100 \mathrm{~g}^{-1}$ in light ( 12 foot-candles) and $2.6 \mathrm{ml} \mathrm{O}_{2} \mathrm{~min}^{-1} 100$ $\mathrm{g}^{-1}$ in dark. In one experiment the preretinal oxygen tension was $17 \mathrm{~mm} \mathrm{Hg}$ in dark, $23 \mathrm{~mm} \mathrm{Hg}$ in room light, and $29 \mathrm{~mm} \mathrm{Hg}$ in 800 foot-candles white light while the arterial blood oxygen tension stayed at $123 \mathrm{~mm} \mathrm{Hg}$ (Fig. 2).

Breathing $100 \%$ oxygen raised the preretinal oxygen tension to $190 \pm 72 \mathrm{~mm} \mathrm{Hg}$ (mean $\pm \mathrm{SD}, n=4$ ) in 12 foot-candles of light (Fig. 3).

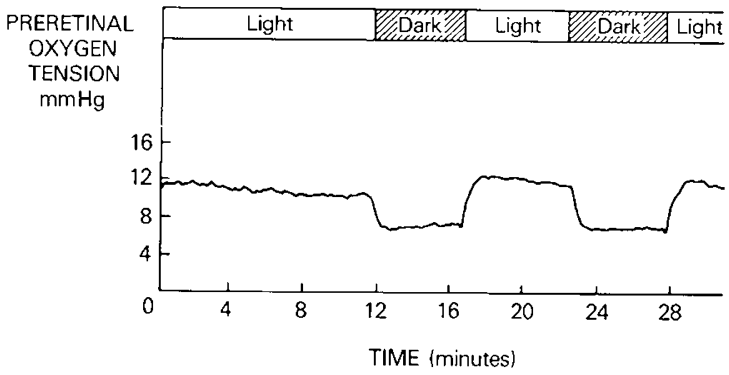

Fig. 1. Preretinal oxygen tension in the rabbit. The oxygen tension is higher in light than dark. Light is 12 foot-candles of white light (General Electric Watt Miser) measured at the level of the cornea with the pupil fully dilated.

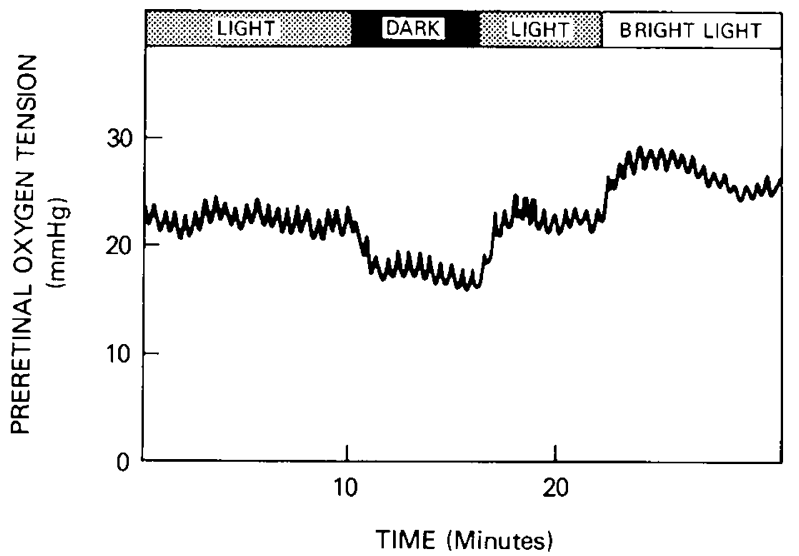

Fig. 2. Preretinal oxygen tension in air breathing rabbit. The rabbit was initially in room light ( 12 foot-candles), then the lights were turned off (dark). The room lights were turned on again (light) and subsequently a bright light ( 800 foot-candles at the cornea) was aimed at the eye. The preretinal oxygen tension shows a close relationship to the light levels. 


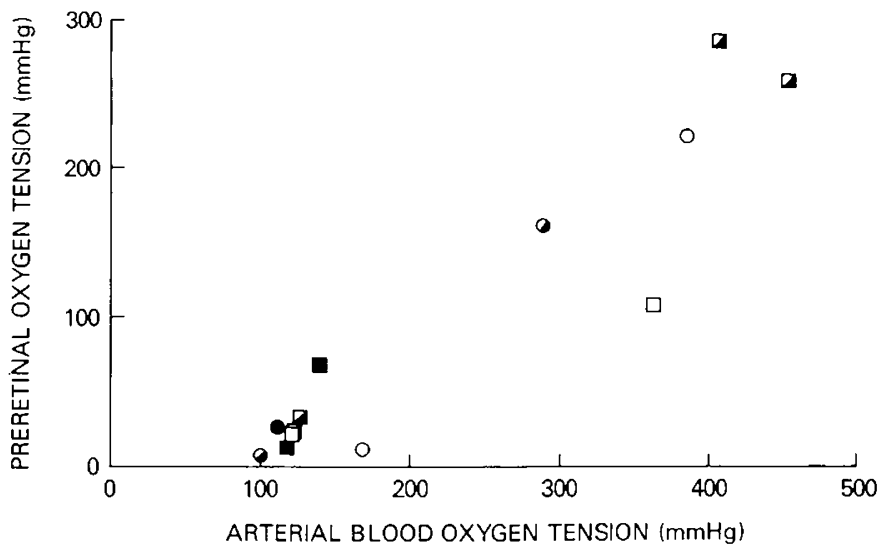

Fig. 3. Preretinal oxygen tension as a function of arterial blood oxygen tension in 12 foot-candles illuminance. Different labels are used for each experimental animal.

\section{DISCUSSION}

The oxygen tension at the retinal surface is lowest in the dark and rises with increased illumination. This corresponds to, and is probably caused by, lower oxygen consumption of the retina in light compared to the retina in the dark. The finding of decreased retinal oxygen tension in the dark is in agreement with our previous report on hyperoxic cats (11), rhesus monkeys (3), and recent reports by Tillis et al. (12) and Linsenmeier (13).

In humans, the increased retinal oxygen tension in light should lead to autoregulatory vasoconstriction (14) in the retina and reduced retinal blood flow in vascularized retinas in light as has been observed in the human retina $(15,16)$.

The calculated oxygen consumption of 2.4 (light) -2.6 (dark) $\mathrm{ml} \mathrm{O}_{2} \mathrm{~min}^{-1} 100 \mathrm{~g}^{-1}$ is in good agreement with in vitro studies. Cohen and Noell (17) found the retinal oxygen uptake in adult New Zealand White rabbit retina to be $2.8-3.3 \mathrm{ml} \mathrm{O} 2 / \mathrm{min} / 100$ $\mathrm{g}$ and considerably less in young rabbit retinas. In vitro studies of retinal oxygen consumption in frogs have shown increased oxygen uptake in dark compared to light $(18,19)$. Our data shows this effect in vivo in a mammalian retina.

When the rabbits breathed $100 \%$ oxygen at one atmosphere, the preretinal oxygen tension rises to $190 \mathrm{~mm} \mathrm{Hg}$. The high rate of blood flow in the choroid allows oxygenation of the retina and choroid from dissolved oxygen alone (5). The choroidal and retinal oxygen tension can stay above the dissociation pressure of oxyhemoglobin and still supply the oxygen needs.

The calculation of retinal oxygen consumption in vivo is based on several assumptions, notably that the arteriovenous oxygen tension fall in the choroid is small enough to be ignored and that the oxygen flux across the internal limiting membrane of the retina is negligible. These assumptions are reasonable in the air breathing rabbit. O'Day et al. (20) have shown the choroidal blood flow in the rabbit to be about $0.84 \mathrm{ml} / \mathrm{min}$. Hemoglobin carries $1.34 \mathrm{ml}$ oxygen on each $\mathrm{g}$ of oxyhemoglobin (21) and in a rabbit with a hematocrit of $35 \%$ the choroidal blood has 0.135 $\mathrm{ml}$ oxygen available per min if the oxyhemoglobin is fully saturated. We have measured the retinal oxygen consumption of the rabbit in vitro to be $5.6 \mu \mathrm{l}$ of oxygen per min (22) and the current data indicated lower oxygen consumption in vivo. To supply the retina with oxygen, the arteriovenous oxygen tension difference in the choroid only needs to be $14 \mathrm{~mm} \mathrm{Hg}$ or less and our assumption that the choroidal oxygen tension equals the arterial blood oxygen tension is reasonable. However, if the oxygen tension rises above the dissociation pressure of oxyhemoglobin, this assumption is no longer valid. When the rabbit breathes $100 \%$ oxygen, the arterial oxygen tension rises to $300-$ $500 \mathrm{~mm} \mathrm{Hg}$. The oxygen requirements of the retina now come from oxygen dissolved in blood. Blood only carries $30 \mathrm{nl} \mathrm{O}_{2} / \mathrm{ml}$ $\mathrm{mm} \mathrm{Hg}$ of dissolved oxygen and a large arteriovenous oxygen tension difference is needed to supply the retina with oxygen (21). This will cause the choroidal oxygen tension to be markedly lower than the arterial blood oxygen tension and the difference between the arterial blood oxygen tension and the preretinal oxygen tension cannot be used to calculate the retinal oxygen consumption. Additionally, the assumption that the oxygen flux across the internal limiting lamina of the retina is negligible may not be realistic when the rabbit is breathing $100 \%$ oxygen. Therefore, we have calculated the oxygen consumption of the retina solely based on the observation in rabbits breathing $21 \%$ oxygen.

The sensitivity of the developing (avascular) retina to the oxygen breathing may be related to the retinal oxygen tension being extraordinarily high in hyperoxic conditions, especially if the subject is also in bright light such as in a neonatal intensive care unit. Glass et al. (2) recently reported that premature infants have a higher risk of retinopathy of prematurity (retrolental fibroplasia) if they are kept in bright light (60 foot-candles). They suggest that light may be a risk factor for the development of retinopathy of prematurity. Oxygen is a well-established risk factor in retinopathy of prematurity (1) and bright illumination may increase the risk of retinopathy of prematurity by raising the retinal oxygen tension, as the present report demonstrates.

While increased retinal oxygen consumption in dark is most probably responsible for the decreased retinal oxygen tension in dark, an alternate explanation is possible. Parver et al. $(23,24)$ have shown scleral temperature elevations that indicate increased choroidal blood flow in response to light shone in the eye being measured or the fellow eye in man and monkey. They used a very bright light source (indirect ophthalmoscope at $7.5 \mathrm{~V}$ setting) possibly similar to our operating microscope light. Increased choroidal blood flow may be a factor in raising chorioretinal oxygen tension in very bright light.

\section{REFERENCES}

1. Patz A 1968 The role of oxygen in retrolental fibroplasia. Trans Am Ophthalmol Soc 66:940-985

2. Glass P, Avery GB, Subramanian KN, Keys M, Sostek AM, Friendly DS 1985 Effect of bright lights in the hospital nursery on the incidence of retinopathy of prematurity. N Engl J Med 313:401-404

3. Stefánsson $\mathrm{E}$, Wolbarsht $\mathrm{ML}$, Landers $\mathrm{MB} 1983$ In vivo $\mathrm{O}_{2}$ consumption in rhesus monkeys in light and dark. Exp Eye Res 37:251-256

4. Stefánsson E 1981 Ocular oxygenation and neovascularization. University Microfilm, Ann Arbor, $\mathrm{MI}$

5. Alm A, Bill A 1970 Blood flow and oxygen extraction in the cat uvea at normal and high intraocular pressures. Acta Physiol Scand 80:19-28

6. Elgin SS 1964 Arteriovenous oxygen difference across the uveal tract of the dog eye. Invest Ophthalmol Vis Sci 3:417-426

7. Wise GN, Dollery CT, Henkind P 197 I Calculation of retinal oxygen diffusion In: The Retinal Circulation. Harper and Row, New York, pp 104-106

8. Alm A, Bill A 1972 The oxygen supply to the retina. II. Effects of high intraocular pressure and of increased arterial carbon dioxide tension on uveal and retinal blood flow in cats. Acta Physiol Scand 84:306-319

9. Thews G 1960 Die Sauerstoffdiffusion im Gehirn. Ein Beitrag zur Frage der Sauerstoffversorgung der Organe. Pflugers Arch Ges Physiol 271:197-227

10. Thews $G 1968$ The theory of oxygen transplant and its application exchange in the lung. In: Lubbers DW, Luff UC, Thews G, Witz GS (eds) Oxygen Transport to Blood and Tissue. Georg Thieme Verlag, Stuttgart, pp 1-20

11. Stefansson E, Wolbarsht ML, Landers MB, Metz G, Cooke D 1980 Light reduces retinal oxygen consumption in vivo. Physiologist 23:21, no. 106

12. Tillis TN, Schmidt GJ, Weiter JJ 1986 In vivo light and dark oxygen measurements under normoxic conditions in the avascular rabbit retina. Invest Ophthalmol Vis Sci 27(suppl):318, no. 86

13. Linsenmeier RA 1986 Effects of light and darkness on oxygen distribution and consumption in the cat retina. J Gen Physiol 88:521-542

14. Hickam JB, Frayser R 1966 Studies of the retinal circulation in man. Circulation 33:302-316

15. Feke GT, Zuckerman R, Green GJ, Weiter JJ 1983 Response of human retinal blood flow to light and dark. Invest Ophthalmol Vis Sci 24:136-141

16. Riva CE. Grunwald JE, Petrig BL 1983 Reactivity of the human retinal circulation to darkness: a laser doppler velocimetry study. Invest Ophthalmol Vis Sci 24:737-740

17. Cohen LH, Noell WK 1960 Glucose catabolism of rabbit retina before and 
after development of visual function. $J$ Neurochem 5:253-276

18. Sickel W 1972 Retinal metabolism in light and dark. In: Fuortes MFG (ed) Handbook of Sensory Physiology VIII/2: Physiology of Photoreceptor Organs. Springer Verlag, New York, pp 667-765

19. Zuckerman R, Weiter JJ 1980 Oxygen transport in the bullfrog retina. Exp Eye Res 30:117-127

20. O'Day DM, Fish MB, Aronson SB, Pollycove M, Coon A 1971 Ocular blood flow measurements by nuclide labelled microsphere. Arch Ophthalmol $86: 205-209$
21. Ganong WF 1973 Gas transport between the lungs and the tissues. In: Review of Medical Physiology Publications. Los Altos, CA, pp 482-483.

22. Sutherland FS, Hatchell DL, Stefánsson E, Reiser HG Hatchell MC 1986 In vitro oxygen consumption of normal and diabetic rabbit retina. Invest Ophthalmol Vis Sci 27(suppl 3):309, no. 36

23. Parver LM, Auker CR, Carpenter DO, Doyle T 1982 Choroidal blood flow. II. Reflexive control in the monkey. Arch Ophthalmol 100:1327-1330

24. Parver LM, Auker CR, Carpenter DO 1983 Choroidal blood flow. III. Reflexive control in human eyes. Arch Ophthalmol 101:1604-1609

\section{Announcement \\ SEARCH FOR EDITOR-IN-CHIEF PEDIATRIC RESEARCH}

After five years of distinguished and devoted service, Dr. Delbert A. Fisher will complete his term as Editor-in-Chief of Pediatric Research on December 31, 1988. The term of Dr. Fisher has been marked by rigorous growth of the journal, a remarkable increase in the number and quality of manuscripts published, a notable decrease in the interval between acceptance and publication of contributions, and a vigorous but constructive process of manuscript review. The American Pediatric Society, Society for Pediatric Research, and European Society for Pediatric Research join with the Board of Trustees in expressing their indebtedness to Dr. Fisher and his Editors for their extraordinary performance in advancing the development of Pediatric Research as an outstanding and unique biomedical publication.

The Board of Trustees has established a Search Committee to review the credentials of qualified candidates and to make recommendations to the Board which has the responsibility for the final selection.

The Search Committee seeks candidates or recommendations for individuals who might serve as Editor-in-Chief. The office carries a budget for supporting staff and an honorarium. Interested individuals should submit six copies of their curriculum vitae and that of at least four individuals in their locale to serve as Editors and a statement about goals, expectations, and future plans for Pediatric Research by March 1, 1988, to:

Dr. Melvin M. Grumbach

Chairman, Search Committee for Pediatric Research

Department of Pediatrics

University of California San Francisco

San Francisco, CA 94143 